\title{
Life is Experienced Until We Die: Effects of Service-Learning on Gerontology Competencies and Attitudes Toward Aging
}

\author{
Sally Hill Jones
}

\begin{abstract}
This mixed methods study examined the effects of service learning in an undergraduate gerontology course on student learning outcomes. Eleven of thirteen students chose to provide companionship and practical help to community-dwelling older adults and link course assignments to this experience. Participating students were mostly female and social work majors or minors, of various races and ethnicities, and of traditional and nontraditional ages. Self-ratings using the Geriatric Social Work Competency Scale showed significant skill improvements for students from pretest to posttest. Analysis of student journals indicated improvement in interaction skills, knowledge of aging processes, dismantling of stereotypes, awareness of issues affecting healthy aging, valuing older adults, and cultural competence. Career plans were positively affected for most students. Letters offering advice to their 70-year old selves appeared to impact students' plans for self-care. Service-learning is recommended to increase students' gerontology competencies and attitudes toward aging in others and themselves.
\end{abstract}

Keywords: Service-learning, gerontology, competencies

\section{INTRODUCTION}

With the burgeoning growth of the older adult population comes the well-established need for social workers trained in gerontology (Bureau of Labor Statistics, 2010). Social workers encounter older adults in a variety of settings, and therefore need skill development to work effectively in this area. Engaging students in the field of gerontology can be difficult due to stereotypical beliefs or lack of experience with older adults, although progress is being made in this endeavor (Cummings \& Galambos, 2002; Mason \& Sanders, 2004). Service-learning exposes students to direct encounters with older adults, which when connected to assignments, has the potential to challenge learners' beliefs about aging and the value of gerontology work, as well as increase their gerontology competency levels. This mixed methods study examined the effects of service learning in an undergraduate gerontology course on student learning outcomes.

\section{BACKGROUND}

Service-learning is an educational approach that ties experiential learning specifically to course objectives through assignments and equally benefits the students and community. It differs from experiential education, which does not include the intentional connection to assignments, and also from internships, which are designed to primarily benefit students (King, 2003; Lemieux \& Allen, 2007). Bringle and Hatcher (1997) defined service-learning as a:

Sally Hill Jones, Ph.D., is an Associate Professor in the School of Social Work at Texas State University, San Marcos, Texas. This research was funded by the Texas State University Service-Learning Initiative Faculty Fellows Program.

Copyright (c) 2011 Advances in Social Work Vol. 12 No. 1 (Spring 2011), 94-112 
Type of experiential education in which students participate in service in the community and reflect on their involvement in such a way as to gain a further understanding of course content and of the discipline and of its relationship to social needs and an enhanced sense of civic responsibility (p. 153).

Benefits of service-learning have been demonstrated in many studies. These include increases in students' civic attitudes, ability to solve social problems, and positive individual development; however, evidence of its effectiveness is limited by the use of varying definitions and standards of service-learning (Boyle, 2007).

Service-learning has been described as particularly suited to the field of social work, but underutilized. King (2003) outlined the compatibility between service-learning and social work core values, while also pointing out the paucity of examples in social work literature. Lemieux and Allen (2007) acknowledged the natural fit between servicelearning and social work's emphasis on social justice. However, their examination of published research supporting this fit revealed the need for substantial development to catch up with the general service-learning field and with the promise described in social work literature. They also found that most of the literature described projects that did not include direct involvement with clients. King and Lemieux and Allen called for further research in these areas.

Recent examples of service-learning in social work include use in an undergraduate research course (Knee, 2002), a graduate policy course (Rocha, 2000), a Maymester experience at a children's burn camp (Williams, King, \& Koob, 2002), an innovative field model (Poulin, Kauffman, \& Silver, 2006), and cross-cultural learning in introductory social work courses (Sanders, McFarland, \& Bartolli, 2003). These authors described positive results in students' self-efficacy, policy skill competencies, political activity, attitudes toward research, scores on field evaluation practice skills, and qualitative differences in cross-cultural learning.

Service-learning has also been used in gerontology to enhance learning, overcome students' negative beliefs and perceptions of work with older adults, and increase the likelihood of students choosing careers in the field. Cohen, Hatchett, and Eastridge (2006) presented an overview of intergenerational service learning, describing vital components, outlining advantages and challenges, and providing several examples for use in graduate foundation social work courses. Among the benefits listed were students' exploration of and changes in attitudes toward older adults and their own aging, as well as improved university-community relationships. Anstee, Harris, Pruitt, and Sugar (2008) presented a model for including service-learning in undergraduate gerontology courses. The Foundation for Long Term Care's decade-long development and study of gerontology service-learning in 28 colleges included social work and several health-care professions (Hegeman, Horowitz, Tepper, Pillemer, \& Schultz, 2002). Results included positive ratings by students, agencies, and older adults, as well as statistically significant positive changes in student attitudes toward older adults. However, no significant changes occurred in student attitudes toward community service or careers in gerontology. Vandsberger and Wakefield (2005) studied students' experiences of a 10hour intergenerational service-learning component in an undergraduate practice class. 
Although no change in majors were found, students exhibited stronger desires to explore gerontology career options.

Others who have introduced service-learning in undergraduate gerontology courses described improved student attitudes toward and desire to work with older adults, reduced myths about aging, better understanding of course concepts and the realities of long-term care, and an increase in positive feelings of self-worth, efficacy, and skills (Blieszner \& Artale, 2001; Brown \& Roodin, 2001; Gutheil, Chernesky, \& Sherratt, 2006; Singleton, 2007). Laganà (2003) offers several creative ideas for students to become involved in service-learning research aimed at improving older adults' quality of life. Bringle and Kremer (1993) specifically studied the effect of intergenerational service-learning on students' attitudes toward their own aging and reported increased positive attitudes. A recent study measured geriatric competencies in a small sample of mostly graduate social work students before and after a service-learning gerontology course (Dauenhauer, Steitz, Aponte, \& Faria, 2010). The authors found significant positive differences pre and posttest, as well as between service-learning and non-service learning students.

This study builds upon existing research in intergenerational service-learning in social work in several ways. It studies service-learning involving direct client contact, called for by Lemieux and Allen (2007). Geriatric competencies are measured in undergraduate social work students, which has not been a focus of the literature. Analysis of students' journal themes offers insight into the learning processes of intergenerational service-learning. A reflection tool is also described that guides students to link their awareness of others' aging realities with their own.

\section{METHOD}

\section{Procedure}

In an elective undergraduate for-credit course introducing students to social work with older adults, enrollees chose a 10-hour intergenerational service-learning project or a research paper. Offering this option was based on discussion in the literature of possible negative effects when service is mandated (Parker-Gwin \& Mabry, 1998; Rama, Ravencroft, Wolcott, \& Zlotkowski, 2000). Although the course was elective, it was one of the few choices for students with required minors in social work or gerontology. The service-learning option also required students to provide their own transportation to older adults' residences in a rural community.

Mutual Adoption Pact (MAP) is an established university program providing gerontology service-learning opportunities for courses across this large university campus. MAP employees screened and assessed community-dwelling older adults in need of assistance, and paired each older adult with a service-learning student who offered companionship and practical help. For the social work course, service-learning students were required to spend at least ten hours with their assigned older adults, who were referred to as MAP clients. Initial class sessions included content on stereotyped beliefs about aging and basics of interviewing older adults, as well as role plays to 
practice interviewing skills. Handouts were provided summarizing class content on how to get started, including making introductions, clarifying expectations, possible conversation topics, and maintaining boundaries. A multidimensional assessment, intervention plan, and policy analysis were based on students' experiences with their older adult clients.

Service-learning students also completed seven journal entries that tied their service experiences to course material. The initial entry was completed before meeting the older adult, followed by five entries, each covering two meetings. The seventh and final journal entry was a summary of what students learned from their experiences with their MAP clients. The instructor provided specific instructions for each entry and a sample. Journal entries were to include meeting descriptions, feelings and thoughts about the relationship process, and how specific course content covered during that time period pertained to MAP clients and their situations. Based on the idea that students learn more easily when they relate personally to concepts being taught, students were required to include letters to themselves at age 70. In these letters, they offered advice based on course content and experiences with their MAP clients.

Students who chose the research paper option also completed the assessment, intervention plan, and policy analysis, based on an older adult they located themselves. They were not required to spend 10 hours with the older adults or to complete journals or letters to their future older selves, instead submitting a research paper on a topic related to course content. All students gave final presentations on the most important course learning and completed pre and posttests measuring self-rated geriatric competencies in the first and last class meetings.

The university internal review board approved the research. The study was designed to determine the effect of the course on students' ratings of their gerontology skills. In addition, the research explored students' experiences interacting with older adults, in particular changes in their attitudes toward older adults and their own aging.

\section{Participants}

Thirteen students completed the course, with 11 choosing the service-learning project. Twelve were female. Seven were Caucasian, three African American, two Hispanic, and one Asian American. Eight were traditional students, while five were nontraditional. Three majored in social work and one was a social work pre-major. Other majors were psychology, urban and regional planning, exercise and sports science, recreation administration, health and wellness promotion, art, and health administration. Nine students had minors, five in social work and four in gerontology. Although 10 hours were required, the mean time students spent with their older adult partners was 19.2 hours $(S D=8.41)$, with a median of 16 hours and range of 10 to 36.5 hours. Ten of the 11 service-learning students exceeded the required number of hours.

Non-service-learning students were female and of traditional age, one Caucasian and one Hispanic. They held majors in exercise/sports science and recreation administration, with one minor in social work and one in gerontology. 


\section{Measurement}

Quantitative and qualitative measures were used to measure learning outcomes. Students completed the Geriatric Social Work Competency Scale II (GSWCS) (DamronRodriguez, 2006) in the first and last class periods to measure students' ratings of their gerontology skills. Ratings were on the following Likert scale: 0 (not skilled at all - I have no experience with this skill); 1 (beginning skill - I have to consciously work at this skill); 2 (moderate skill - this skill is becoming more integrated in my practice); 3 (advanced skill - this skill is done with confidence and is an integral part of my practice); and 4 (expert skill - I complete this skill with sufficient mastery to teach others). The scale's 40 items describe skills important to social work with older adults in four domains of 10 items each: Ethics and Theoretical Perspectives; Assessment; Intervention; and Aging Services, Programs and Policies. The maximum total score is 160 and 40 for each domain. The instrument has reported convergent validity and strong internal reliability (Nakao, Damron-Rodriguez, Lawrance, Volland \& Bachrach, 2008). It has been used by the John A. Hartford Partnership Program for Aging Education (Social Work Leadership Institute, 2010) to measure competencies of foundation graduate social work students. It was chosen as the appropriate measure because undergraduate social work majors are considered in the field to be learning material comparable to foundation level master's students.

The researcher also analyzed the content of student journals and final presentations on course learning using qualitative content analysis. After an initial reading to get a general sense of the content, journals and final presentation summaries were read several times to determine and confirm emerging themes and categories. The number of nonservice-learning students $(n=2)$ was too small for meaningful comparisons with servicelearning students.

\section{RESULTS}

\section{Quantitative}

Means for domain and total scores on pretests and posttests were compared, using paired samples $t$-tests. As shown in Table 1, posttest scores were significantly higher than pretest scores on total competency mean scores and the four domains. Students progressed from initial ratings of having no or beginning skills to being moderately skilled at the course's end. The largest increases in skill ratings were in the domains of Assessment and Aging Services, Programs and Policies, which were initially the lowest rated domains. The smallest increase was in the Values, Ethics, and Theories domain, which also had the highest ratings at the start and end of the course. Because students' number of contact hours varied, Pearson's correlations were computed for contact hours and mean competency scores. No significant correlations were found. 
Table 1. Pretest/Posttest Mean Scores for All Students $(\mathbf{N}=13)$

\begin{tabular}{llll}
\hline & \multicolumn{2}{c}{ Mean scores } & Significance \\
\cline { 2 - 4 } $\begin{array}{l}\text { Geriatric Social Work } \\
\text { Competency Scale }\end{array}$ & Pretest & Posttest & \\
\hline Values, Ethics \& Theories & $1.84(0.71)$ & $2.91(0.53)$ & $t(12)=-4.18^{*}$ \\
Assessment & $1.07(0.88)$ & $2.70(0.71)$ & $t(12)=-6.22^{* *}$ \\
Intervention & $1.36(0.85)$ & $2.57(0.93)$ & $t(12)=-4.92^{* *}$ \\
Services, Programs \& Policies & $1.05(1.05)$ & $2.56(1.00)$ & $t(12)=-5.23^{* *}$ \\
Total Scores & $1.33(0.77)$ & $2.69(0.73)$ & $t(12)=-5.84^{* *}$ \\
\hline
\end{tabular}

Note: Standard deviations are in parentheses.

${ }^{*} p<.01 ;{ }^{* *} p<.001$.

\section{Qualitative}

Qualitative data provided depth and indicated rich learning had occurred. The researcher examined students' journals and final presentation summaries several times, extracting common themes. Categories emerged from service-learning students' journal entries, letters advising their 70-year old selves, and final journal entries summarizing what they had learned in the course. Students' final presentations on applications of course learning also generated common themes.

\section{Journal: Developmental process of relationship-building.}

An overarching theme in students' journals was the developmental process of building relationships with older adults. Subthemes emerged within each relationship phase.

Prior to the initial meeting, students described nervousness and anticipation, with fears of being boring, not knowing what to say, or having misunderstandings. They also described hopes and desires to be helpful and learn from older adults. One student noted, "He is 82 years old and would be the oldest person I have ever met - I am nervous about our interactions." Another student stated, "I hope to learn from her and prevent making the same mistakes she made." They described class discussions and materials as helping them feel more prepared in areas of maintaining confidentiality, active listening, and showing respect.

In describing the beginning phase of the relationship, three subthemes emerged. Students were becoming more comfortable, as indicated by one student's comment that “. . . the second meeting was much more vibrant ... I feel that already she is getting more 
comfortable with me being around.” They also appeared to struggle with maintaining appropriate boundaries. One student stated, "I notice she has little control of her hands should I ask? I'm glad we talked about this in class.” Other examples of comments included a student who wrote, "I need to know when to keep my views to myself," and "She asked me lots of questions and wanted to take me with her to church." A third subtheme was the challenge to students' beliefs about aging, indicated by comments in their journal entries that aging is not a disease, and that older adults can still learn, are not necessarily hard of hearing, and still have romantic lives.

In the middle phase of the relationships, it was clear that many students were feeling closer to their MAP clients. One student reported, "We are getting to know one another more and more each day; our relationship has grown into a very open one." Another stated, "I look forward to our games during each visit - I have to say one of the highlights of visiting with my client is seeing her face light up when I get there because for that time she gets to do her favorite thing." A third example was a student's comment that, "I actually felt very close to Mrs. X today - she and I really 'let our hair down' so to speak today. She is an endearing person and I am so glad I was matched with her.” Students described helping clients with tasks of cleaning, organizing, setting up online account systems, shopping, and enrolling in home-delivered meals programs. They also observed psychological or physiological aspects of aging discussed in class.

Some students encountered barriers and frustrations as their involvement increased. One student wrote, "She was not there three times . . . asked her and she was embarrassed . . . maybe she needs a calendar." Another student described her struggle, "I've noticed that she is comfortable living in a cluttered and unclean environment ... the amount of stuff she has accumulated would take days and weeks to remove or organize - I don't understand this." However, deeper understanding often followed, such as when the student later stated, "I realized that these things I thought was just stuff are her keepsakes and it reminds her of her past."

As they struggled with barriers, some students hit upon new ways to relate to their MAP clients. A student assigned to an older adult in a long-term care facility became frustrated with her partner's reluctance to engage in conversation or participate in arts and crafts projects she planned. Applying her skills as an urban and regional planning major, the student discovered a way to connect with the older adult. Using a laptop computer and program that displayed current images of geographical locations, the student gave her MAP client a virtual tour of places that were meaningful to her. These included the home and church in which the older adult grew up, the campus of the university she attended, the nursing home where her sibling resided, and her child's new business, all located in other states. The student reported that this activity thrilled her MAP client and brought new life to their interaction.

As the semester concluded, students described feelings about ending with their MAP clients that revealed the attachments they had formed. For example, one student stated, "I wonder what will happen to him; there are just a few more weeks remaining for the semester," and "Our last visit was more difficult for me then I had originally anticipated." Many students decided to continue the relationships. They also wrote comments 
evaluating their experiences, such as, "We have built an open relationship - one I have not had sense the passing of my own grandmother," and "Working with Ms. X will be an experience that will remain with me through my life - so much of what she has taught me and shared with me has been inspiring.”

\section{Journal: Racial, ethnic, and religious differences.}

Experiencing and grappling with racial, ethnic, and religious differences were commonly discussed in student journals. Students appeared to be at various levels of cultural competence and to increase cultural awareness, knowledge, and skills from their experiences.

Some students described increased awareness of cultural differences and reflected on biases in themselves and others. For example, an African American student went shopping with a Caucasian client and was taken aback that the salesperson assumed they were not together. An Asian American student confronted her stereotyped beliefs when she was surprised that a Mexican American senior cooked healthy foods. In another situation, a Caucasian student struggled to identify whose biases were involved when her Caucasian MAP client complained that nursing facility staff members where she lived spoke only Spanish around her.

Some students reported increased awareness of generational differences within the same ethnic group. For example, an African American student described discovering a difference with her African American MAP client: "She told me 'race and culture only plays a significant role in your life if you are weak and let it' - African American elderly I have grown up around set boundaries on their own freedom.” A Caucasian student described being challenged in a different way when learning about generational differences from her African American MAP client:

In my studies of racism I have found a lot of people that feel we aren't doing enough to end racism, whereas Mrs. $X$ thinks the Black youth don't appreciate that they have a place in society and it's nothing like when she was growing up it was eye-opening to me and reminds me not to start thinking things are a particular way.

Journals also indicated students gained knowledge of other cultures from interacting with their MAP clients. A Caucasian student paired with an American Indian older adult described valuable learning from attending cultural events with her and discussing her beliefs. An Asian American student applied knowledge of societal oppression in understanding her African American MAP client. She connected his deep distrust of medical professionals to discrimination he had encountered and historical uses of deceptive medical practices with persons of color.

Students also demonstrated culturally-informed interaction skills with their MAP clients. One example occurred in the introductory phone call, described by a Caucasian student: 
The client said, 'You need to know that I am black.' I said okay, and that it won't bother me if it doesn't bother her and she laughed and thought that was good. . . I hope she has not had someone from the school discriminate when visiting.

One African American student negotiated cultural differences with her Caucasian MAP client at several points in the relationship. She initially reported comments indicating the older adult had little experience with people of other races. Description of improvement followed:

I believe my client has become more comfortable being around someone of a different culture and ethnicity. I believe that she is starting to see beyond the color of my skin and seeing me as an individual. She grew up during a different time than I have and she may still carry some prejudices and stereotypes but I can tell that she is making a conscious effort.

The student then encountered a situation in which she felt treated like a servant or "White Lady's Companion." She questioned the validity of her perception, but set reasonable limits on the older adult's expectations. The student worked hard to "keep the relationship in perspective," since she believed the older adult saw herself as a mentor. At the semester's end, the student recognized multiple realities in the situation, feeling "more like a protégé than a hired companion," while also acknowledging structural inequities. A productive partnership was forged, while the student also made plans to advocate for the oppressed in the community.

Students also appeared to increase their awareness, knowledge, and skills in the area of religious differences. Initially, many students noted that their MAP clients were active in their religions. One student explained, "The spiritual aspects of aging are going to be a new thing to me also since I was not raised under any strict religious guidelines.” They learned about different faiths and also demonstrated skills in this arena. For example, one student stated, "I am a religious person, but it is really important that I keep my beliefs and opinions about religion to myself." Another student noted, "We have different religious beliefs but I try to find common ground." As relationships progressed, many students appreciated the important role religious communities played in clients' lives, providing social and spiritual support, as well as meaning.

\section{Journal: Independence.}

Students' journal entries indicated an increased awareness of the importance of independence as one ages. They observed challenges to remaining independent and talked with their MAP clients about planning for the time when more care is needed. Students noticed that older adults' independence was affected by their home situations and that they preferred to live at home, even in a dysfunctional situation, rather than in a long-term facility. Students also noticed financial concerns influencing independence, such as the comment, "She needed four additional prescriptions which has really set her back financially." Health status was a third factor of independence noted, as students observed the impact of health challenges. 


\section{Journal: Family and social support.}

Another pervasive theme in students' journals was the importance of family and social support in later life. Students observed the value of quality relationships with family and friends and their effect on the aging process. For example, one student wrote, "I believe that what she needs from me is for someone to pay her some attention, listen to her or be the daughter or grandchildren she does not get to see." Another student described, "She expresses her strong desire to let all of her family know she loves them and has appreciated them - it is so beautiful.” Students saw pets as crucial in older adults' support systems, such as the student who explained:

The family has adopted a small dog for the house and I can see how it has had a positive effect on her. She remembers his name and picks him up and lets him lick her - she loves that dog. The dog has her reaching down and petting him and getting her to move around.

\section{Advice to 70-year old self.}

In letters students wrote giving advice to themselves at age 70, several themes emerged that paralleled descriptions of their MAP clients' aging. Themes included physical self-care, staying active, managing independence/dependence, maintaining social and family relationships, financial planning, staying organized, benefits of pets, and having a positive attitude about aging.

Taking good care of their physical health was a strong subtheme in the advice, exemplified by the following statements: "Take care of your body - you only have one;" "Your body is not a prison, it is your vehicle in life as Mrs. X advised you;" and "Keep up with your doctor's visits and follow your doctor's instructions - this is extremely important - get plenty of exercise, go for a walk every day.” At times, the advice was for their younger selves:

I am of course hoping that in the next 44 years there will be many scientific breakthroughs ... however if science stays at a standstill then you will have to start now to live a healthy lifestyle and age gracefully.

Staying active was another subtheme in the advice letters. Examples included: "Although I may have some degenerative diseases does not mean that I cannot stay active;" "If you keep moving, motion is lotion to your bones, joints, and muscles;" and "I would advise you to always keep in touch with technology, it is your friend, it can make life easier and more enjoyable." Again, some advice was preventive: "I should develop and build more healthy activities today. I will start building the audio book library.”

Just as students observed independence as key for their MAP clients, students gave advice to their 70-year old selves about independence and accepting help, such as "I hope I continue to stay open minded so that I do not close out the help that is available to me.” Another student advised, "Remember that you can retain your independence while accepting assistance.” More specific advice came from an older student: "Please allow others to help you when you truly need it; you know that if you need assistance getting 
organized, you cannot ask your children because they will not have the patience, so ask grandchildren." Practical advice included, "Live in an area where you have access to groceries and doctors," "Give up driving when you are scared to drive, have had others mention that your driving is lousy, or by instinct know that it is time," and "Make sure you have a house you can get around in." Some students referred to psychological help for depression or grief, such as “... take the time and fully devote immediate attention to grief ... Seek out the counsel of a close friend, therapist, or pastor who is willing to listen ... Or just date the young ones so you go first.”

Students recognized the crucial role social relationships will play in their healthy aging, as they had observed in their MAP clients. Several examples included, "I hope you are still pleasant to be around so that way you don't get lonely," and "Don't be the cliché grumpy old man like your grandpa was because kids will be afraid of that." One student paired with a woman in a long-term care facility wrote, "Make friends wherever you go especially in the lunchroom because that may be the only way to get a refill on tea."

Staying involved in the community was also seen as important, exemplified by the comment, "Make sure you are well connected to your environment like neighbors, friends or staff so you can be involved in plenty of activities and remain in people's consideration." One student wrote, "Try to live in a town with a college so you can have student helpers like this."

Maintaining ties with family was strong advice and sometimes preventive. One student stated, "I need to improve my relationships with others, such as with family and friends - as I get older I want to have a good support system and be a support to others." Another student's comments summarized this advice:

Keep your family close - I hope in all these years you haven't cut any ties with anyone in your family... it seems to me that family surrounds us when we enter this world and I hope that it is family that is surrounding us when we leave it.

Maintaining healthy boundaries was part of students' advice about family relationships, sometimes humorously stated. For example, one student advised, "Don't let your children live with you when they can grow a beard.” Another wrote:

Learn to say NO to your children when they get older. Know where your boundaries should be and stick to them. Know that there is a time to help and a time to not. Know and understand what an enabler is.

Student comments indicated an awareness that it was necessary to expand their circles of support since family may not be available. One student wrote "Don't let your age dictate the age of your friends - just as people come in all shapes and sizes so do friendships and that is what my client has shown me.” Another comment expanded on this idea:

I know you sometimes worried about having a relationship with your children but your client has showed you that it isn't necessarily your blood family who are the ones who you have a close relationship with but those who you have mentored over the years and adopted who have now become your family. 
Finances and future planning were also seen as essential. Warnings to save money and stay out of debt were common, such as, "If I save up money now, I will be more secure when Social Security runs out," "Begin investing more money immediately after college ... wean your friends and relatives off now," and "Plan ahead no matter how morbid you think it is.”

Organization and clutter was a minor theme. Advice included, "Buy a scanner and shred" and "I beg of you to not keep so many things around." One student offered practical advice after helping her MAP client decorate for the holidays, "Keep Christmas lights on the cardboard.”

Based on observations of pets helping older adults, students recommended pets for their old age. One student wrote, "Find time to involve myself with animals ... the joy they bring her is more than can be explained and I hope that I can have that same companionship.” Other students made decisions about specific pets they would get, exemplified by this statement, "70-year old self, first things first you're going to get a dog whether you want one or not - it will improve your mood and give you companionship when there is no one around to visit with you."

Students offered recommendations on keeping positive attitudes about aging. Examples included, "Life does not end when you get 'old', only that the challenges in life change” and "I must keep a 'can-do' attitude and try new opportunities.” One student decided, "I want to make a promise to myself that I never quit on life." Another advised, "Keep painting your toe nails funky colors and be the cool grandma." Finally, a student recommended the following:

Enjoy the sunshine and the fact that you have two functioning legs on which to walk on. Love and live life to the fullest and don't let a day go by that you do not mention something that you are thankful for... keep on laughing never lose your sense of humor because you are definitely going to need it.

\section{Final journal entry: What I learned.}

In their final journal entries, students summarized what they learned from interacting with their MAP clients. Several themes emerged.

Patience was a consistent theme in what students stated they learned from the experience. For example, "It has shown me the value in taking my time so things are done correctly."

Once again, the importance of personal and professional relationships came through as a theme in student learning. One student described, "My client has taught me that the relationships you build with other people can last a life time whether they are good or bad." Another stated, "I have learned that building healthy relationships are important when being a social worker - if you do not build healthy relationships with your clients they will not open up to you." A third student remarked, "It only takes a little bit of time to improve someone’s quality of life.” 
Many students described acquiring skills in relating to older adults. They described becoming good listeners and taking into consideration physical limitations. Some were more specific, such as, "I have learned how to interact with someone in early stages of dementia." Another student described learning to be more attentive and present:

I was a task master with this MAP client and one day he said to me, hush and just slow down. You worry too much and you do too much. I did not realize this because I thought that's what he needed me for, which is to get things done. Wrong!

Students also reported expanding their knowledge of aging processes, individual differences, and faulty stereotypes. Examples were: "It is good to know that depression is not a normal aging process;" "I also believe that we learn until we die. I have also seen that life didn't take my client down the road that she had visualized;" and "Physical ailments as well as mental do not stop one from living - age is not a disease or a disaster, only an extension of our life.”

\section{Final Presentations: Application of Course Learning}

All students gave brief presentations at the end of the course reporting how they will apply their learning to two areas, the first being their own aging. They described decisions to change current physical health habits (eating, exercise), to focus on relationships so they are not alone in old age, and to plan practically for their later years. They also described changes in attitudes about aging, feeling more optimistic about the aging process, as well as fearing death less than before. Some described learning the necessity of preparing financially for old age.

The second area addressed application of what they learned to interactions with older adults. Most students described building healthy and meaningful relationships with older adults, particularly listening well, being sensitive and patient, respecting and valuing them, and focusing on the person when dementia takes over. One student wrote:

Learning how to build this relationship was huge step for me because I have always been afraid of conversation with the elderly. I feared that I would not be able to relate to them, but now I am certain I can do it.

Some students described increasing their knowledge of elder abuse and learning the importance of including older adults in decisions concerning them. One student stated, "The one most important thing I am taking away from this course that I will use when interacting with older adults is that they were just like me at one point and I will be just like them at some point."

\section{Changes in Future Plans}

In journal entries or final presentations, students indicated changes in future plans as a result of the course. One student described an overall impact: "I have gained more knowledge in talking with her about her life and the obstacles that she has overcome and in doing so have reexamined my own life and the direction I would like to go.” Others described plans to become advocates for older adults, particularly for elder-friendly 
communities. One student decided to involve her community service organization in a volunteer arts and crafts project at the nursing home. She also became involved in forming a student gerontology club the following semester.

Ten of thirteen students indicated some movement toward gerontology careers. One student indicated a definite new decision to work in the field of dementia care, announcing she had obtained a job in a dementia care facility and found her career path. The student least certain about change indicated she began the course only wanting to work with children but now would not limit herself. Five students described confirmation or increased clarity about their decisions to work in gerontology. Of these, two narrowed their interests to long-term care, exemplified by this statement, "Now I know what my next set of goals will be after I receive my LCSW - I am going to look into opening my own long term care facility.” Three students described increased interest in gerontology work. For example, one student decided to explore "where I can take my career to change the way America sees the elderly, nursing homes, and their involvement and place in the physical community and society." Another student stated, "This semester the experience with our MAP client ... has moved me closer to working with the older adult by way of seeing that life is experienced until we die.”

\section{DISCUSSION}

Several findings from this study have potential importance for gerontology education, given the limitations of the small non-representative sample and use of self-report instruments. Results suggest that intergenerational service-learning in social work can be a valuable pedagogy. Through relationships with older adults, guided reflections, and assignments tying experiences to course objectives, rich learning occurred. Significant improvement was reported in gerontology competency skill ratings and many areas found by others (Brown \& Roodin, 2001; Cohen, Hatchett \& Eastridge, 2006; Vandsberger \& Wakefield, 2005). Career plans were reconsidered, confirmed, or refined, with most students describing plans to use the skills learned in their chosen fields, similar to findings of Vandsberger and Wakefield. Students appeared to progress on the continuum of interest in aging outlined by Gorelik, Damron-Rodriguez, Funderbunk, and Solomon (2000), and these findings support their suggestion for gerontology courses that include interactions with older adults to be offered to undergraduates. Further research needs to include essential components of intergenerational service-learning outlined in the literature that tie experiences to course objectives, distinguishing it from experiential learning and internships. In this way, a body of work can be built based on a common definition. A scale measuring career plan movement could also capture such changes quantitatively.

Findings suggest that a tool such as the Geriatric Social Work Competency Scale is promising as an effective measure of student ratings of gerontology skill development. The scale could be used to compare effectiveness of teaching methods and measure levels of increasingly advanced skills in gerontology programs. The posttest ratings in this study were in the moderate range, compared to the advanced ratings of the graduate students in the study by Dauenhauer, Steitz, Aponte, and Faria (2010), suggesting a progression through educational levels may be measured. Although more research is needed using the 
scale, this study suggests its use should be studied at the undergraduate level. Including independent ratings of student competencies and feedback from older adult participants may produce a fuller picture of student outcomes.

As social work education becomes increasingly competency-based, the GSWCS is also a potentially useful tool to demonstrate social work programs' compliance with accreditation standards. Competencies measured in the GSWCS are compatible with the 2008 Educational Policies and Accreditation Standards (EPAS) of the Council on Social Work Education (CSWE), used to guide social work educational curricula (CSWE, 2008). Many skills listed in the GSWCS overlap with CSWE standards, as applied specifically to work with older adults. Measuring gerontology competencies could therefore demonstrate student learning outcomes.

Intergenerational service-learning may enable students to demonstrate many competencies in actual relationships rather than in case studies. For example, Educational Policy (EP) 2.1.1 (p.3), which focuses on identifying and behaving as a professional social worker, outlines the importance of personal reflection, professional boundary management, and career-long learning, all of which students had the opportunity to practice in this course. Another key area in which students demonstrated competencies is EP 2.1.4, which involves diversity in practice (p.4, 5). Students in this course demonstrated positive learning outcomes described in many components of this standard, as they engaged diversity on multiple levels in interactions with MAP clients. Students also demonstrated skills of engagement, assessment, and intervention described in EP 2.1.10 (p.6, 7), applied knowledge of human behavior in social environment (EP 2.1.7, p. 6) and analyzed policies affecting older adults' well-being (EP 2.1.8, p.6).

The relationship-building process was a significant theme in the qualitative findings, supporting the notion that a one-on-one relationship with an older adult is a significant aspect of gerontological service-learning (Dauenhauer, Steitz, Aponte, \& Faria, 2010; Vandsberger \& Wakefield, 2005). Assisting students through the phases of relationshipbuilding is therefore warranted to ensure positive experiences for all. Practical guidance for the initial interview and maintaining boundaries, as well as role plays may help students allay early anxieties and gain confidence in their abilities, as suggested by others (Blieszner \& Artale, 2001; Brown \& Roodin, 2001; Laganà, 2003). Attending to frustrations and barriers as relationships progress may deepen students' understanding of older adults and prevent misunderstandings. Students also may need assistance negotiating the ending process. Research of effective methods of fostering relationships in intergenerational service-learning could contribute to its success.

An important finding was that student letters to themselves at age 70 fostered intentional connections of course learning to planning for their own aging, with positive results. This assignment set the stage for students to expect reciprocal learning and to gain personally from the experience. Tying course material to students' personal lives also appeared to enliven classroom discussions. This student group entered with fairly high interest in gerontology, given the number with gerontology minors and interest in the field. However, guided reflections that focus on students' aging processes, within the context of intergenerational relationships, may contribute to overcoming reluctance of 
younger, less interested students by making the material personally relevant. Research in this area is sparse and may be productive to investigate further.

Another key finding was students' learning about cultural differences. The servicelearning project offered rich opportunities to increase cultural awareness, knowledge, and skills. The potential for this type of learning is invaluable for students at all points along the cultural competency continuum. In a review of culturally competent social work practice, Kohli, Huber, and Faul (2010) recommended that students be "immersed in cultural experiences where they observe the uniqueness of every individual” (p. 268). Intentionally matching students and older adults to enhance cross-cultural learning is one way to provide such opportunities and prepare students for work with diverse older adult populations. More focused investigation is needed into cultural aspects of intergenerational service-learning, specifically in social work. Sanders, McFarland, and Bartolli (2003) advocated for specific measures of changes in students' perceptions of cultural differences. Measurement of cultural knowledge and skills would also be valuable, as would research that includes experiences of students from oppressed populations who encounter prejudicial attitudes in older adults during service-learning projects.

The substantial time requirement for faculty and students in implementing servicelearning projects has been described as a barrier (Hegeman, Horowitz, Tepper, Pillemer, \& Schultz, 2002; Rocha, 2000). The university program that located and assessed the needs of community-dwelling older adults and matched them with students was invaluable. As suggested by King (2003), advocating for such institutional support is highly recommended.

For student time investment, ten to thirty hours seemed adequate for these students to significantly increase competency ratings and experience qualitative changes. Within this range, number of hours did not seem to affect competency ratings. Interestingly, the student who spent 10 hours made the most decisive career change. Ten hours appeared feasible to students initially, perhaps contributing to their willingness to participate, and many chose to invest more time. Of the many variables that potentially impact outcomes in service-learning projects, number of contact hours may be worth further investigation to inform future project planning.

Service-learning in gerontology education has the potential to open students' minds to the complex realities of aging, for others and themselves, and to increase their competence in building productive relationships with older adults across a broad spectrum of diversity. As one student put it, "I have learned a lot about older adults through my meetings with my MAP client that you would not have gotten out of reading a textbook." As such, the needs of the growing older adult population, social work profession, and society compel further development and study of the effective components of gerontology service-learning. 


\section{References}

Anstee, J. L. K., Harris, S. G., Pruitt, K. D., \& Sugar, J. A. (2008). Service-learning projects in an undergraduate gerontology course: A six-stage model and application. Educational Gerontology, 34(7), 595-609.

Blieszner, R., \& Artale, L. M. (2001). Benefits of intergenerational service-learning to human services majors. Educational Gerontology, 27(1), 71-87.

Boyle, M. E. (2007). Learning to neighbor? Service-learning in context. Journal of Academic Ethics, 5(1), 85-104.

Bringle, R., \& Hatcher, J. (1997). Reflection. College Teaching, 45, 153-158.

Bringle, R., \& Kremer, J. (1993). Evaluation of an intergenerational service-learning project for undergraduates. Educational Gerontology, 19(5), 407-416.

Brown, L. H., \& Roodin, P. A. (2001). Service-learning in gerontology: An out-ofclassroom experience. Educational Gerontology, 27(1), 89-103.

Bureau of Labor Statistics. (2010). Occupational Outlook Handbook, 2010-11 Edition, Social Workers. Washington, DC: U. S. Department of Labor. Retrieved from http://www.bls.gov/oco/ocos060.htm

Cohen, H. L., Hatchett, B., \& Eastridge, D. (2006). Intergenerational service-learning: An innovative teaching strategy to infuse gerontology content into foundation courses. Journal of Gerontological Social Work, 48(1/2), 161-178.

Council on Social Work Education. (2008). Educational policies and accreditation standards. Retrieved from http://www.cswe.org/File.aspx?id=13780

Cummings, S., \& Galambos, C. (2002). Predictors of graduate students' interest in agingrelated work. Journal of Gerontological Social Work, 39(3), 77-94.

Damron-Rodriguez, J. A. (2006). Moving forward: Developing geriatric social work competencies. In B. Berkman (Ed.), Handbook of social work in health and aging (pp. 1051-1068). New York: Oxford University Press.

Dauenhauer, J. A., Steitz, D. W., Aponte, C. I., \& Faria, D. F. (2010). Enhancing student gerocompetencies: Evaluation of an intergenerational service-learning course. Journal of Gerontological Social Work, 53(4), 319-335.

Gorelik, Y., Damron-Rodriguez, J., Funderbunk, B., \& Solomon, D. H. (2000). Undergraduate interest in aging: Is it affected by contact with older adults? Educational Gerontology, 26(7), 623-638.

Gutheil, I. A., Chernesky, R. H., \& Sherratt, M. L. (2006). Influencing student attitudes toward older adults: Results of a service-learning collaboration. Educational Gerontology, 32(9), 771-784.

Hegeman, C. R., Horowitz, B., Tepper, L., Pillemer, K., \& Schultz, L. (2002). Service learning in elderly care: Ten years of growth and assessment. Journal of Gerontological Social Work, 39(1/2), 177-194. 
King, M. E. (2003). Social work education and service learning. The Journal of Baccalaureate Social Work, 8(2), 37-48.

Knee, R. T. (2002). Can service-learning enhance student understanding of social work research? Journal of Teaching in Social Work, 22(1/2), 213-225.

Kohli, H. K., Huber, R., \& Faul, A. C. (2010). Historical and theoretical development of culturally competent social work practice. Journal of Teaching in Social Work, 30(3), 252-271.

Laganà, L. (2003). Using service-learning research to enhance the elderly's quality of life. Educational Gerontology, 29(8), 685 -701.

Lemieux, C. M., \& Allen, P. D. (2007). Service learning in social work education: The state of knowledge, pedagogical practicalities, and practice conundrums. Journal of Social Work Education, 43(2), 309-325.

Mason, S. E., \& Sanders, G. R. (2004). Social work student attitudes on working with older clients. Journal of Gerontological Social Work, 42(3), 61-75.

Nakao, K. C., Damron-Rodriguez, J., Lawrance, F. P., Volland, P., \& Bachrach, P. S. (2008). Validation of the Practicum Partnership Program Geriatric Social Work Competency Scale II (GSWC Scale II). Research That Matters, January 17-20. Retrieved from http://sswr.confex.com/sswr/2008/techprogram/P8250.HTM

Parker-Gwin, R., \& Mabry, J. B. (1998). Service learning as pedagogy and civic education: Comparing outcomes of three models. Teaching Sociology, 26(4), 276291.

Poulin, J., Kauffman, S., \& Silver, P. (2006). Serving the community and training social workers: Service outputs and student outcomes. Journal of Social Work Education, 42(1), 171-184.

Rama, D. V., Ravencroft, S. P., Wolcott, S. K., \& Zlotkowski, E. (2000). Servicelearning outcomes: Guidelines for educators and researchers. Issues in Accounting Education, 15(4), 657-694.

Rocha, C. J. (2000). Evaluating experiential teaching methods in a policy practice course: The case for service-learning to increase political participation. Journal of Social Work Education, 36(1), 53-61.

Sanders, S., McFarland, P., \& Bartolli, J. S. (2003). The impact of cross-cultural servicelearning on undergraduate social work students' perceptions of culture, race, and economic justice. The Journal of Baccalaureate Social Work, 9(1), 19-40.

Singleton, J. L. (2007). Taking the class to the community with service-learning: Gerontological macro social work practice. Journal of Gerontological Social Work, 50(1/2), 105-118.

Social Work Leadership Institute. (2010). The Hartford Partnership Program for Aging Education. Retrieved from http://www.socialworkleadership.org. 
Vandsberger, E., \& Wakefield, M. (2005). Service learning with rural older adults: Effects on students' career perspectives in gerontology. Journal of Intergenerational Relationships, 3(4), 83-97.

Williams, N. R., King, M., \& Koob, J. J. (2002). Social work students go to camp: The effects of service-learning on perceived self-efficacy. Journal of Teaching in Social Work, 22(3/4), 55 - 70.

\section{Author's note:}

Address correspondence to: Sally Hill Jones, Ph.D., Associate Professor, School of Social Work, Texas State University, 601 University Drive, San Marcos, TX 78666. Email: sh29@txstate.edu 